\title{
Analysis of Barriers to the Deployment of Health Information Systems: a Stakeholder Perspective
}

\author{
Alan Serrano ${ }^{1}$ (D) Javier Garcia-Guzman ${ }^{2} \cdot$ Georgios Xydopoulos $^{3} \cdot$ Ali Tarhini $^{4}$
}

Published online: 30 June 2018

(C) The Author(s) 2018

\begin{abstract}
This paper argues that the cross-analysis of barriers with stakeholders provides a richer picture than analyzing the barriers on their own, as most of the literature in this area does. To test this hypothesis, we used the data from 33 interviews across 19 different types of stakeholders that were involved in a telemedicine system for the Chronically-ill Patient. Our findings show encouraging results. For instance, it was found that the group of stakeholders who are directly related to the governance and policy-making identified most of the barriers. This finding may imply that this group is more aware of the challenges when implementing HIS, or it may suggest that this group poses more resistance due to the current economic and Organizational models in health care. It was also found that some barriers are cited by all stakeholders whereas others not, suggesting that some barriers may be more relevant than others.
\end{abstract}

Keywords Healthcare $\cdot$ Information systems $\cdot$ Telemedicine $\cdot$ Chronic diseases $\cdot$ Barriers $\cdot$ Stakeholder theory

\section{Introduction}

\subsection{Context}

A large number of systems can be considered an e-Health system, and therefore there are different ways of classifying them (e.g. telemedicine, e-health, Health Information Systems (HIS)). To avoid misinterpretations, in this article the names "e-health" and Healthcare Information Systems (HIS) will be used to refer the same kind of systems.

Alan Serrano

csstaes@brunel.ac.uk

Javier Garcia-Guzman

jgarciag@inf.uc3m.es

Georgios Xydopoulos

g.xydopoulos@uea.ac.uk

Ali Tarhini

alitarhini@squ.edu.om

1 Brunel University London, Uxbridge UB8 3PH, UK

2 Universidad Carlos III de Madrid, Avenida de la Universidad 30, Leganés, 28911 Madrid, Spain

3 University of East Anglia, Norwich NR4 7TJ, UK

4 Sultan Qaboos University, P. O. Box: 20, P. C.: 123 Muscat, Sultanate of Oman
The particular system under analysis in this research could be classified as office/hospital-based, store-and-forward, and home-based telemedicine (Hersh et al. 2002). In office/hospital-based telemedicine, both patient and clinician are in a hospital or a healthcare professional office, and the information is sent in real time. In store-and-forward systems data is transmitted but is reviewed in later steps. In home-based telemedicine patients are at home or in a residential setting and communicate with healthcare professionals directly by the use of an electronic device, such as PDA, mobile phone, or wireless computers. The context of this article is home-based telemedicine systems for the chronically ill patient. Those systems are usually oriented to facilitate independent living, better communication, supervision and coordination among healthcare services and improve self-management skills for those patients with chronic conditions (Duplaga and Zielinsky 2006; Koch 2006).

\subsection{Motivation}

There is a well-established body of literature that looks into the barriers that hinder the adoption of HIS. For example, some studies investigate barriers in particular types of HIS, such as Teleradiology and Telepathology (Martínez Álvarez et al. 2011) or Electronic Medical Records (Barbarito et al. 2015), and others looking into more generic HIS (Currie and Seddon 2014). Within the literature available, however, there 
are some limitations. For instance, different authors use different ways of classifying the barriers, making challenging to compare amongst them. There is also a limited consensus on identified barriers and categories. This limited agreement about what can be expected from the adoption of those systems could be one of the reasons for the delay in the adoption of HIS (Hebert and Korabek 2004; Gruber et al. 2009; Williams et al. 2003). There is also a large number of studies that focus on a particular set of stakeholders' groups, namely, healthcare professionals, GPs, managers and policymakers. These groups may create bias by adopting their particular view of this phenomenon, but more importantly, they do not offer an integrated view that considers all groups' perspectives. The different views adopted by these groups also produce different lists of the identified stakeholders. Different actors involved in those systems will have different perceptions and attitudes towards them, and there is little agreement about the potential benefits and the barriers to overcome (Fitzgerald et al. 2008).

One limitation that can be seen across most of the studies found in the literature is that they omit or underemphasize the role that the stakeholders have in the identification of these barriers. Some research papers do not report the stakeholders that were used to identify the barriers, while others report the stakeholders but do not make a clear cross-analysis between the stakeholders and the barriers. The authors of this paper argue that it is imperative to understand not only the barriers but also who has reported them. These relationships can help to understand better the nature and relevance of the barriers of HIS implementation that need to be surmounted and the stakeholder groups that need to be involved in the analysis to overcome them.

In addition to these points, there is a reduced number of studies using a qualitative approach to study HIS (Yusof et al. 2006). Quantitative methods of research are the most commonly used in the medical domain. HIS, however, is a multidisciplinary field and the use of qualitative methods can help to add new and different insights. The complexity of human factors involved in the adoption and use of those systems and the very nature of the healthcare work make it necessary for a different approach (Holden and Karsh 2010). Therefore, an approach that considers all views of all different groups and that adopts a qualitative approach could help to derive a more comprehensive view of the problem, as it will be shown in this article.

The purpose of this research work consists of identifying the barriers to the deployment of home-based telemedicine systems for the chronically ill patient using Stakeholder Theory in the scope of one case study. Stakeholder Theory is used for the identification of the stakeholders involved in home-based telemedicine systems, essential to provide a holistic view of the barriers to the adoption of such systems and the associated challenges to overcome them. To this end, this article is organized as follows: Section 2 discusses a general overview of the benefits and barriers to adopting HIS previously reported in the literature and provides the grounds to justify this research effort. Section 3 outlines the use of Stakeholder Theory within the context of this research. Section 4 describes the case study carried out in the scope of this research work. Section 5 presents the barriers identified in the scope of this research work. In Section 6 we present our conclusions and possible research avenues. Finally, Section 7 summarizes the implications of this research.

\section{Benefits and Barriers to the Adoption of HIS: a Review}

A systematic literature review approach was implemented to investigate the well-built body of knowledge related to the benefits and barriers of HIS adoption and to establish a robust evidence-base that can certify the need of a more comprehensive cross-analysis of barriers attached to specific stakeholders. This review can help to understand better the nature and relevance of the barriers of HIS implementation that need to be surmounted and the stakeholder groups that need to be involved in the analysis of how to overcome them. To this end a systematic literature review process was established which included:

- Review a range of published literature in HIS implementation and the stakeholders that are involved in it in a systematic manner

- The in-depth examination of studies, meeting the predetermined inclusion and exclusion criteria, to assess the quality of the study and extract evidence in support of the in-depth review.

- The development of a framework for data analysis and identification of key themes.

- Reporting and dissemination

The first stage of the process involved the identification of papers, research reports and policy documents that were broadly concerned with interventions related to HIS implementation in databases like EBSCO, Emerald Text, ScienceDirect, and Wiley-Interscience.

Keywords and phrases like "Health Information Systems Adoption", "Health Information Systems barriers" "Health Information Systems adoption stakeholders", "HIS stakeholders", "HIS benefits" were derived from the research question. The keyword list was refined to include only words which had produced relevant results. Initial searches yielded a total of 77,568 results. To reduce the number of potential papers to a manageable level a significant proportion was screened online to determine their suitability for inclusion in the systematic literature review. Duplicates among databases 
were also excluded. During the online screening, references that were conducted before 2005 and were not written in English or did not centrally address the research question were excluded. This task was usually performed by looking at the title, but in some instances, the abstract was used (this depended on the transparency of the title). The number of references in 'Inclusion' at this stage totaled 76.

The findings show that HIS are considered to deliver many benefits for health institutions and Organizations that implement them. The possible benefits of Health Information Systems adoption have been widely studied to the extent there is a reasonable consensus of the benefits that these types of systems may bring to the Organizations that adopt them. Nextthere is a brief sample of the benefits found in the literature:

- Allow more informed and efficient decision making (Barbarito et al. 2015).

- Improve the quality of care of individuals by allowing them to access and use the information needed to effectively communicate with other patients and medical practitioners concerning their health care (Barbarito et al. 2015; Paré et al. 2014).

- It can solve the logistical organization problems associated with paper systems (Paré et al. 2014).

- Offer general social and economic benefits (Currie and Seddon 2014)

- Empower individuals to have more control over their health status (Currie and Seddon 2014)

- Allow access to health independent of geographic barriers (Martínez Álvarez et al. 2011; Chapman and Arunatileka 2010).

- Assist health Organizations to reduce costs and increase cost-effectiveness (Martínez Álvarez et al. 2011; Eron 2010; Gruber et al. 2009).

- Help in delivering new and integrated services (Khatri et al. 2011; Hoerbst et al. 2010).

- Improve clinical evolution of the disease treatment (Eron 2010; Polisena et al. 2010; Cheng et al. 2009).

- Increase patient quality of life (Polisena et al. 2010)

- Improve the role of patients and their families in their treatments (Cheng et al. 2009; Koch 2006)

The literature that discusses the barriers of e-Health systems adoption, however, is less common and more importantly, there are fewer agreements amongst authors. The differences are not only about the identification of the barriers but also about identifying the different stakeholders that are involved in the design, development and deployment of HIS.

Table 1 summarizes the findings of our literature review highlighting the type of stakeholders used for the research and the barriers reported.
The first conclusion that arises from the analysis of the literature is that there is an increasing number of publications over the years, but the consensus in the identified barriers is still limited. Some authors list the barriers without any classification making it very difficult to generalize findings and compare amongst authors. Other authors prefer to produce categories of barriers to then position the barriers within those categories. For generalization purposes, the latter approach is more convenient; however, there is still a disagreement on the categories found amongst different authors (Barbarito et al. 2015; Helena 2016; Paré et al. 2014; Pouloudi and Whitley 1997; Vos and Achterkamp 2006; Mantzana et al. 2007).

Another observation from our review is that the majority of the studies in healthcare information systems research fail to report the stakeholders involved clearly, or they have been limited to use principal stakeholders such as healthcare professionals, GPs, managers, and policymakers. This approach does not reflect the complexity of the HIS networks, in which, there are a significant number of actors involved from different Organizations or groups. Indeed, in home-based telemedicine systems, patients and their families or carers could be the primary users of these types of systems. Nurses, doctors and other health-related professionals, however, are also users with different needs and perceptions. Managers can belong to different healthcare Organizations because most HIS try to join in the same network of different health-related organization s, such as hospitals, primary care, and secondary care. The need for gathering information of key stakeholders in the healthcare information systems area has been extensively recognized in the academic literature (Lyons et al. 2005; Pouloudi and Whitley 1997). Most of the time, however, their identification remains limited to the most obvious ones without following a more structured way of categorizing them (Mantzana et al. 2007; Pouloudi and Whitley 1997; Vos and Achterkamp 2006).

The last observation is that although many barriers are reported, there is very little information regarding: a) which barriers are more important and should be tackled first (e.g. prioritization), b) which barriers are reported by all stakeholders involved (relevance) or c) which stakeholders report more barriers. There is practically no correlation between the barriers found, their frequency, and the stakeholders that reported them. This information could be beneficial at the time of trying to address those challenges.

These findings were used as the rationale to identify, in a more generic manner, the list of stakeholders involved in home-based telemedicine systems for chronically ill patients with their corresponding views about the perceived barriers. The following section explains the research methods used for this article and how they were combined. 
Table 1 A summary of the literature review on barriers, stakeholders and relevance

\begin{tabular}{|c|c|c|c|c|}
\hline No & Author & $\begin{array}{l}\text { Type of HIS Used in } \\
\text { The Research }\end{array}$ & Stakeholder & Barriers \\
\hline 1 & $\begin{array}{l}\text { (Martínez } \\
\quad \text { Álvarez et al. } \\
\text { 2011) }\end{array}$ & $\begin{array}{l}\text { Teleradiology and } \\
\text { Telepathology }\end{array}$ & $\begin{array}{l}\text { - Department of Health } \\
\text { - NGO } \\
\text { - Health Providers }\end{array}$ & $\begin{array}{l}\text { - Regulation } \\
\text { - Litigation } \\
\text { - Data Safety } \\
\text { - Policy }\end{array}$ \\
\hline 2 & $\begin{array}{l}\text { (Currie and } \\
\text { Seddon 2014) }\end{array}$ & HIS in General & - Not Reported & $\begin{array}{l}\text { - Lack of users' awareness of benefits } \\
\text { - Luck of benefits investigation } \\
\text { - Low e-Health Literacy }\end{array}$ \\
\hline 3 & (May et al. 2011) & Telecare & $\begin{array}{l}\text { - Healthcare Professionals } \\
\text { - Policy Makers } \\
\text { - Patients }\end{array}$ & $\begin{array}{l}\text { - Uncertainty about coherent and sustainable service } \\
\text { - Lack of Financial Motives } \\
\text { - Lack of continuity in regard to the previous service } \\
\text { provision scheme } \\
\text { - Uncertainty regarding the effectiveness of the e-Health } \\
\text { intervention } \\
\text { - Poor implementation }\end{array}$ \\
\hline 4 & $\begin{array}{l}\text { (Moffatt and } \\
\text { Eley 2011) }\end{array}$ & Telemedicine & $\begin{array}{l}\text { - Moderators academics } \\
\text { - Educators } \\
\text { - Healthcare Professionals } \\
\text { - Policy Makers } \\
\text { - Patients }\end{array}$ & $\begin{array}{l}\text { - Funding } \\
\text { - Time } \\
\text { - Implementation } \\
\text { Current Infrastructure } \\
\text { - Lack of Skills }\end{array}$ \\
\hline 5 & $\begin{array}{l}\text { (Roig and Saigí } \\
\text { 2011) }\end{array}$ & HIS in General & $\begin{array}{l}\text { - Clinicians } \\
\text { - IT } \\
\text { - Policy Makers }\end{array}$ & $\begin{array}{l}\text { - High Costs } \\
\text { - Funding Constraints } \\
\text { - Poor leadership and change management }\end{array}$ \\
\hline 6 & $\begin{array}{l}\text { (Shakshuki and } \\
\text { Khalifa 2013) }\end{array}$ & $\begin{array}{l}\text { Electronic Medical } \\
\text { Records }\end{array}$ & - Clinicians & - Human, Organizational and regulation related factors \\
\hline 7 & (Lluch 2011) & HIS in General & - Not Reported & - Human, Organizational and regulation related factors \\
\hline 8 & $\begin{array}{l}\text { (Hill and Powell } \\
\text { 2009) }\end{array}$ & $\begin{array}{l}\text { Electronic Medical } \\
\text { Records General }\end{array}$ & - Not Reported & - Legal, Operational and Financial Factors \\
\hline 9 & $\begin{array}{l}\text { (Gagnon et al. } \\
\text { 2010) }\end{array}$ & HIS in General & - Not Reported & $\begin{array}{l}\text { - Design } \\
\text { - Time } \\
\text { - Uncertainty about coherent and sustainable service } \\
\text { - Lack of Financial Motives } \\
\text { - Lack of continuity in regard to the previous service } \\
\text { provision scheme } \\
\text { - Uncertainty regarding the effectiveness of the e-Health } \\
\text { intervention } \\
\text { - Poor implementation }\end{array}$ \\
\hline 10 & $\begin{array}{l}\text { (Barbarito et al. } \\
\text { 2015) }\end{array}$ & $\begin{array}{l}\text { Electronic Medical } \\
\text { Records }\end{array}$ & $\begin{array}{l}\text { - Patients } \\
\text { - Healthcare Professionals }\end{array}$ & $\begin{array}{l}\text { - Should be accompanied by a correct educational campaign } \\
\text { for patients } \\
\text { - Resistance from the medical practitioners to adopt new } \\
\text { methods }\end{array}$ \\
\hline 11 & $\begin{array}{l}\text { (Ammenwerth et } \\
\text { al. 2003) }\end{array}$ & HIS in General & $\begin{array}{l}\text { - Healthcare Professionals } \\
\text { - Policy Makers }\end{array}$ & - Complexity of HIS \\
\hline 12 & (Paré et al. 2014) & $\begin{array}{l}\text { Electronic Medical } \\
\text { Records }\end{array}$ & $\bullet$ GPs & $\begin{array}{l}\text { - User knowledge } \\
\text { - Financial barriers } \\
\text { - Complexity of the System }\end{array}$ \\
\hline 13 & (Helena 2016) & HIS in General & - Not Reported & - Requires High Short-term investment \\
\hline 14 & (De Vries 2011) & $\begin{array}{l}\text { Inventory Systems in } \\
\text { Health }\end{array}$ & $\begin{array}{l}\text { - Policy Maker } \\
\text { - Admin Staff } \\
\text { - Medical Practitioners } \\
\text { - Pharmacist }\end{array}$ & $\begin{array}{l}\text { - A complex set of interactions and negotiation behavior of } \\
\text { the stakeholders involved } \\
\text { - Multi-dimensional character of Inventory projects }\end{array}$ \\
\hline 15 & $\begin{array}{l}\text { (Kivinen and } \\
\text { Lammintaka- } \\
\text { nen 2013) }\end{array}$ & $\begin{array}{l}\text { Management } \\
\text { information system }\end{array}$ & $\begin{array}{l}\text { - front-line, middle and top-level } \\
\text { managers (nursing, medical, } \\
\text { financial, human resources, IT) }\end{array}$ & $\begin{array}{l}\text { - Negative attitudes toward information systems in } \\
\text { - General and lack of motivation to use the management } \\
\text { information system. } \\
\text { - The lack of motivation to learn }\end{array}$ \\
\hline 16 & $\begin{array}{l}\text { (Saleem et al. } \\
\text { 2015) }\end{array}$ & $\begin{array}{l}\text { Clinical Information } \\
\text { Systems (CIS) for } \\
\text { intensive care units }\end{array}$ & - Clinicians and administrative staff & $\begin{array}{l}\text { - Integration issues with other software systems poor usability } \\
\text { hardware challenges software challenges insufficient } \\
\text { technical support unclear roles and lack of coordination } \\
\text { among stakeholders }\end{array}$ \\
\hline
\end{tabular}


Table 1 (continued)

\begin{tabular}{|c|c|c|c|c|}
\hline No & Author & $\begin{array}{l}\text { Type of HIS Used in } \\
\text { The Research }\end{array}$ & Stakeholder & Barriers \\
\hline 17 & $\begin{array}{l}\text { (Massoudi et al. } \\
\text { 2016) }\end{array}$ & $\begin{array}{l}\text { Electronic Medical } \\
\text { Records General }\end{array}$ & $\begin{array}{l}\text { - Vendors } \\
\text { - Policy Makers } \\
\text { - Admin Staff } \\
\text { - Medical practitioners }\end{array}$ & $\begin{array}{l}\text { - Data quality, completeness, sharing, and transmission } \\
\text { issues; Organizational structure, maturity, and } \\
\text { sustainability issues; and vendor issues }\end{array}$ \\
\hline
\end{tabular}

\section{Research Method}

This study aims to understand the phenomenon through the social groups, and individuals or stakeholders involved in the system and, therefore, the underlying epistemology can be defined as interpretive, in other words, our construction of reality is shaped by the interpretation of reality by human actors (Walsham 2006). The qualitative approach adopted in this research is based on interpretivist epistemology because it is an approach that can help to identify the relationship that exists between the different stakeholder groups involved in HIS and the barriers reported by those groups. Interpretivist epistemology also helps to provide a better understanding of the nature of the barriers from the multiple stakeholders' perspectives that need to be surmounted when adopting this kind of information Systems (Goldkuhl 2012).

The selected method of research was a case study. Case study research offered the potential to provide a richer picture of the influences towards HIS, and the users' and organization s' response to those influences (Yin 2009). Case study research is appropriate to achieve the research aim because the multiple stakeholders' perspectives on HIS adoption barriers could not be understood without taking into consideration the context in which it exists, i.e., hospitals, primary care centers and patients' homes, and the interaction of the different stakeholders. The case study is conducted in Spain and involves a home-based telemedicine system to support chronically ill patients at home (Chronic Obstruction Pulmonary Disease). A more detailed explanation of the case study is presented in section 3.1. The case study was supported and enriched by Stakeholder theory using the guidelines and principles proposed by Pouloudi and Whitley (1997) to identify obvious and not so obvious stakeholders in complex information systems with several Organizations involved.

The stakeholder identification process has helped to improve the documentation of stakeholders or interest groups and individuals involved in complex information systems. This process is especially relevant when factors such as distance and time are inherent in the provision of remote healthrelated services (Pouloudi 1999).

The phases considered for the case study development are detailed below:
1) Case Study Context: The first phase consisted of defining the case study regarding the chronic disease to consider and the HIS implementation to analyze.

2) Organization of stakeholders' groups: The second phase was the organization and characterization of the social groups or stakeholders involved in the systems regarding four groups: Supporters, Controllers, Providers, and Acceptors.

3) Data Gathering: The third phase consisted of collecting the data using several sources: semi-structured interviews with the participants, the study of document and text about the system, a guided questionnaire to the patients, attendance at patients training sessions, attendance at patients' home visits, and direct observation of the system while in use.

4) Data Analysis: The fourth phase was to clean, code, organize and analyze the data collected regarding the barriers identified by the stakeholders.

5) Results verification: The fifth phase was to verify that the barriers identified as relevant during data analysis were perceived in the same way by relevant stakeholders. A second feedback round of interviews was done, where barriers identified as relevant were presented to a group of stakeholders having the same characteristics than involved in data gathering to ask if they perceive those barriers of being important or not.

Figure 1 graphically represents the case study phases and the relationships between them. More detailed information regarding these phases is provided in the following subsections.

\subsection{Case Study Context}

The case study explored the use of mobile technologies to monitor respiratory patients with COPD (Chronic Obstruction Pulmonary Disease) in Spain. Patients with COPD present serious difficulties to exhale normally. Each patient had a mobile phone and two sensors, a spirometer and a pulse oximeter. The spirometer records the amount and the rate of air that is breathed in and out over a specified time frame. The pulse oximeter measures the amount of oxygen in the blood and the pulse. A questionnaire with 10 questions about their 


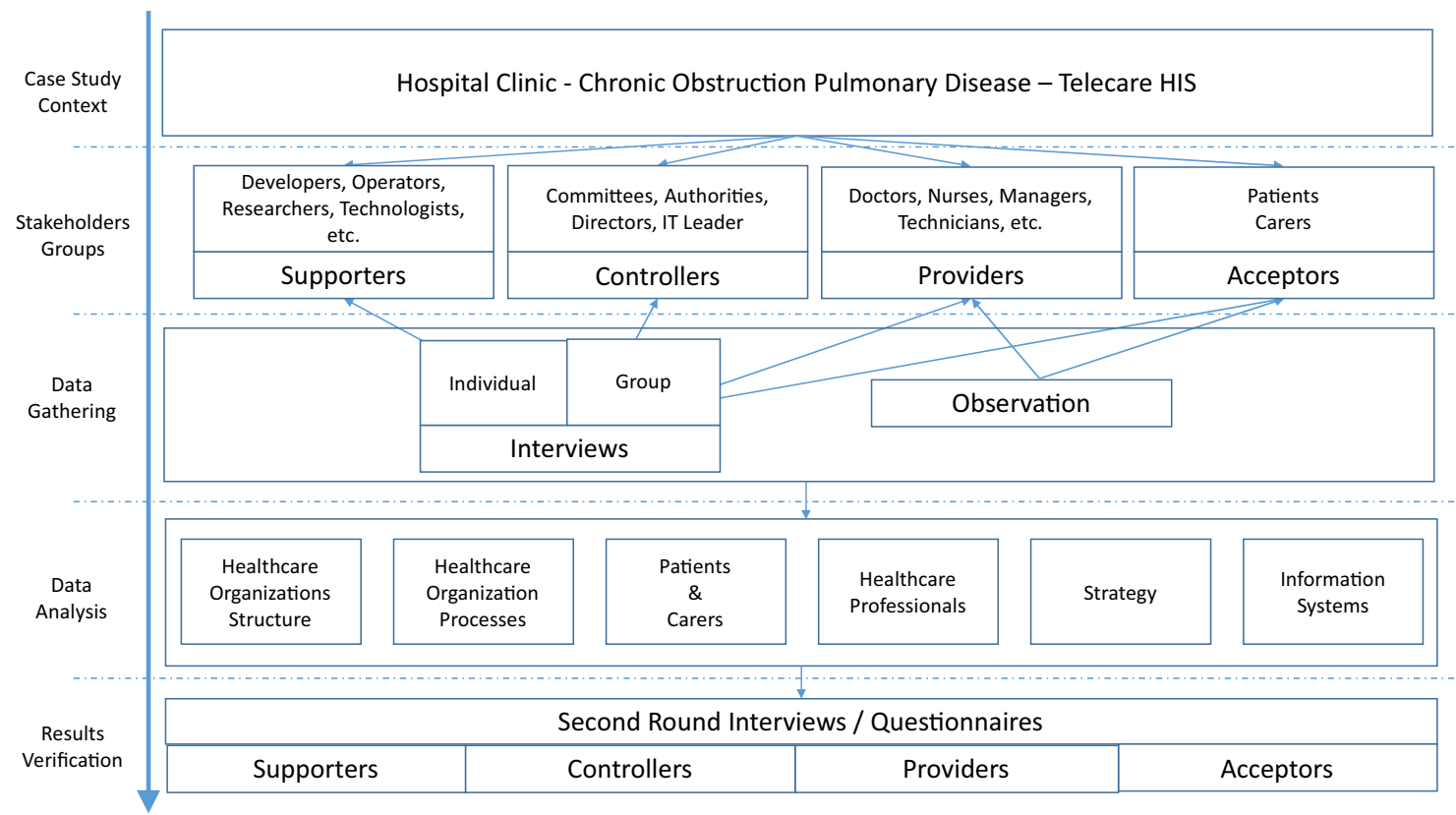

Fig. 1 Phases of the case study development

health condition was conducted on the mobile phone and depending on the answers, two types of alarms were activated. The schedule of monitoring sessions was arranged for each patient, usually daily, and their vital signals were sent through wireless and mobile technologies to the web patient record software. In the case where some of the data was exceeding a threshold, alarms were activated. Health professionals involved in the care team could access the data at any time, via a secure Internet connection.

This project was led by a tertiary private hospital (Hospital Clinic) within the Catalan Health Services. The respiratory unit was responsible for launching the project. The system was developed by a telecommunication company in the USA and is based on a $3 \mathrm{G}$ mobile phone with specific software developed in Java. The main components were a web-based patient management software and two wireless devices: a pulse oximeter and a spirometer connected via Bluetooth with the mobile phone.

A clinical protocol was defined for this group of patients and was provided with the mobile devices plus some training sessions about the use of the technology and the healthcare aspects of the disease, such as pharmacological and lifestyle issues. In case of an emergency, the group had to contact the call center, and a nurse decided what was better for the patient. The options were either come to an emergency room in the hospital, bring a doctor or a nurse to the patient's home, forward the patient to the primary care doctor or adjust the treatment over the telephone.

\subsection{Organization of Stakeholders' Groups}

The case study participants were organized into four main categories, as proposed by Mantzana et al. (2007), i.e. Controllers, Providers, Supporters, and Acceptors. Although the authors do not provide a precise definition for each of the categories mentioned above, in this research are defined as follows:

- Controllers are those actors that have control and govern the implementation of HIS and the policies around it. The participants in this category involved in the case study were organized in five (5) groups: Ethical Approval Committees, General Health Authorities, Medical Directors, Hospital Manager and IT Project Leader. The number of participants involved in this category was five (5).

- Providers are those actors within the health care system that works in conjunction with the HIS. The participants in this category involved in the case study were: Home Support Teams, Specialists Dr., Case Managers, Clinical Technicians, Specialist Nurses and Call Centre Assistants. The number of participants involved in this category was ten $(10)$.

- Supporters help in the development, provision and maintenance of the HIS itself, such as technologists, suppliers, researchers, and academics. The number of participants involved in this category was seven (7).

- Acceptors are the final beneficiaries of the HIS, such as patients and carers. The number of participants involved in this category was seven (7). 


\subsection{Data Gathering}

The initial information collected was in the form of system documentation, the clinical protocols and the patient's information sheets. The objective of this data was to know precise details about the information systems and the context in which the system was implemented. Four sessions of direct observation of the system, while being used by healthcare professionals, were also conducted, and notes were taken. Additionally, three patients' training sessions were attended, where managers trained the patients in how to use the system, assessed them on the difficulties they could have while using it on their own and trained them in how to take the medication and the clinical aspect of the disease.

The primary sources of data were semi-structured openended interviews with the stakeholders involved. The interviews were conducted in their offices, when applicable, and lasted from $45 \mathrm{~min}$ up to $2 \mathrm{~h}$. They were recorded using a digital recording machine, except for two cases in which the individuals refused to be recorded. In these cases, notes were taken during the interviews. The interviewees were selected depending on their involvement in the area, and according to the stakeholder framework, one of the questions was to identify other stakeholders that could also be involved. The first contact was conducted by telephone or e-mail, explaining the research and asking for his/her willingness to participate. A total of 33 interviews were conducted across 19 different groups of stakeholders, during an 8-month period.

To verify that the barriers identified, a second feedback round of interviews were done to ask stakeholders if they perceive those barriers of being important or not. The stakeholders involved in this feedback second round were not the same stakeholders who provided the first identification of barriers. Other people with similar roles, responsibilities and skills in similar context than our case study (use of telemedicine solutions to monitor people having chronic diseases) were involved. The distribution of participants is presented in Fig. 2. The researchers ask their opinions about the relevance of each of the presented barriers in a Likert scale (0 Don't know), 1 - Fully Disagreement, 2 - Partial Disagreement, 3 - Neither Agreement or Disagreement, 4 Partial Agreement, and 5 - Fully Agreement). We used the obtained data to confirm the barriers previously identified.

\section{Data Analysis Using Stakeholder Theory Principles}

The first scheme used to classify the barriers identified by the stakeholders needed was based on Lluch's model (Lluch 2011). Lluch's proposed a model for the categorization of barriers in Healthcare Information Systems (HIS) and it is composed of five categories: 1) Structure of Healthcare

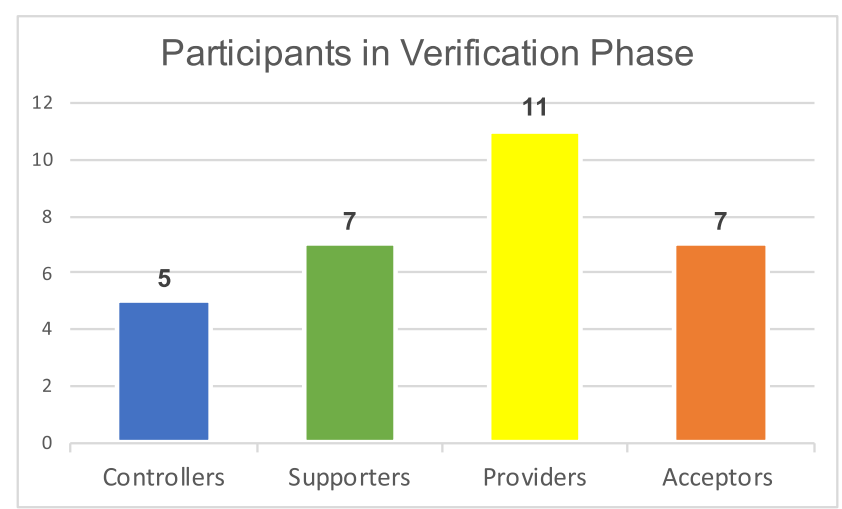

Fig. 2 Characterization of participants involved in the second feedback round of interviews

organizations; 2) Tasks; 3) People Policies; 4) Incentives; and 5) Information and Decision Processes. The Lluch's categorization model was tailored to solve some limitations identified during the data organization phase. The main adaptations and the corresponding justification are detailed below:

a) Tasks. This category represents the way in which work is organized. In barriers terms, it represents how HIS may impact the way of work. Lluch dived this category into Changes in work processes and routines and Face-to-face interaction versus new ways of working. During the data organization phase for purposes of differentiating tasks vs processes, it was decided to rename the category Tasks as Health Care Organizational Processes (HC Organizational Processes) with three subcategories: Processes, Complexity and Support. This change helped to bring more clarity at the time of classifying the barriers and added other factors found during the data organization phase, such as complexity inherited from the application domain and that could be reflected on the processes themselves (e.g. chronic diseases) and Organizational support needed to redesign business processes.

b) People Policies. According to Lluch, Clinicians and similar stakeholders will require specific training depending on their specialties, and this is more evident when it comes to HIS skills. Therefore, training limitations and HIS literacy may present a barrier. The HIS used in this paper involved patients and carers that directly used the system. These stakeholders, however, are not included in Lluch model. It was noticed that most of the subcategories of People and Policies, apart from accountability, could apply to patients and carers. Thus, People Policies was renamed as HC Professionals, and a similar category was added for Patients and Carers with the difference that it does not contain the liability and accountability subcategory.

c) Information and Decisions Processes. In Lluch's model, this category did not include any subcategory. During the 
data organization phase, it was found that some barriers were related to the technology itself, some to decision processes and some to the software. Because IS and IT are critical variables in this research, a more detailed analysis of this category was derived by breaking it down into distinct components. To this end, Paul $(2010 a, b)$ defines information systems in a way that suits this task. In simple terms, Paul defines IS as what emerges from people using IT, where IT can be hardware and software. Based on this definition the Information and Decisions Processes category was re-named as Information Systems, containing five sub-categories: IT Infrastructure, Software Design, IT in use (emerging IS), Results/Impact and Trust.

d) Finally, some barriers could not fit into any of the categories proposed by Lluch or the new categories. These were mostly related to strategic issues of HIS. Thus, a new group, namely Strategy, was added together with three subcategories: Organizational Culture, Organizational Strategy and Finance.

The final categories and subcategories derived from the pilot test are listed in Table 2 together with a short description of each of them.

Once the scheme was redefined for this research the final step was to organize the identified barriers and fit them into the proposed scheme. It was required to interpret barriers with similar meanings so they could be considered to be the same barrier. For example, "Lack of integration with hospital information systems" and "Lack of data integration" were two barriers reported by different individuals but can be considered to have the same meaning; hence they were deemed to be the same barrier reported on two occasions. To avoid bias, this process was done separately by three of the researchers.

Table 2 Data analysis schema

\begin{tabular}{|c|c|c|c|c|c|}
\hline $\begin{array}{l}\text { 1. Healthcare } \\
\text { organizations } \\
\text { structure }\end{array}$ & $\begin{array}{l}\text { 2. HC Organizational } \\
\text { processes }\end{array}$ & 3. Patients and carers & 4. HC Professionals & 5. Strategy & 6. Information systems \\
\hline $\begin{array}{l}\text { Hierarchy } \\
\text { Barriers that } \\
\text { hierarchical } \\
\text { structures may } \\
\text { impose on the HIS } \\
\text { and vice-versa. }\end{array}$ & \multirow[t]{2}{*}{$\begin{array}{l}\text { Processes. Relates } \\
\text { specifically to the } \\
\text { impact that HIS } \\
\text { may have on the } \\
\text { Organizational } \\
\text { processes and } \\
\text { vice-versa. }\end{array}$} & $\begin{array}{l}\text { Training. Relates to } \\
\text { issues arising from } \\
\text { training the patients } \\
\text { and carers in all } \\
\text { aspects of the HIS }\end{array}$ & $\begin{array}{l}\text { Training. Relates to } \\
\text { matters resulting } \\
\text { from training the HC } \\
\text { professionals in all } \\
\text { aspects of the HIS }\end{array}$ & \multirow[t]{2}{*}{$\begin{array}{l}\text { Organizational } \\
\text { Culture. Issues } \\
\text { derived from the } \\
\text { adoption of HIS } \\
\text { that affect the } \\
\text { Organizational } \\
\text { culture. }\end{array}$} & $\begin{array}{l}\text { IT infrastructure. Barriers } \\
\text { specifically concerned } \\
\text { with the IT infrastructure } \\
\text { required to deploy HIS } \\
\text { solutions }\end{array}$ \\
\hline $\begin{array}{l}\text { Team and } \\
\text { Cooperation } \\
\text { Barriers arising from } \\
\text { team and } \\
\text { cooperation } \\
\text { amongst all } \\
\text { stakeholders. }\end{array}$ & & $\begin{array}{l}\text { HC-IT Knowledge. } \\
\text { Relates to the actual } \\
\text { IT Knowledge } \\
\text { required by patients } \\
\text { and carers. }\end{array}$ & $\begin{array}{l}\text { HC-IT Knowledge. } \\
\text { Relates to the actual } \\
\text { IT Knowledge } \\
\text { required by HC } \\
\text { professionals. }\end{array}$ & & $\begin{array}{l}\text { Software Design. Barriers } \\
\text { concerned with the } \mathrm{HC} \\
\text { software and information } \\
\text { design. }\end{array}$ \\
\hline $\begin{array}{l}\text { Legal Frameworks } \\
\text { Barriers that legal } \\
\text { frameworks in the } \\
\text { HC domain may } \\
\text { impose on the } \\
\text { adoption of HIS. }\end{array}$ & $\begin{array}{l}\text { Complexity. Relates to } \\
\text { the complexities of } \\
\text { the HC application } \\
\text { domain itself (e.g., } \\
\text { chronic diseases). }\end{array}$ & $\begin{array}{l}\text { Organizational } \\
\text { Support. Relates to } \\
\text { the Organizational } \\
\text { support patients and } \\
\text { carers require from } \\
\text { the HC organization. } \\
\text { Motivation. Relates to } \\
\text { motivational issues } \\
\text { faced by patients and } \\
\text { carers at the time to } \\
\text { engage with the HIS. }\end{array}$ & $\begin{array}{l}\text { Managerial Support. } \\
\text { Relates to the } \\
\text { managerial support } \\
\text { HC professionals } \\
\text { require from their } \\
\text { managers. } \\
\text { Motivation/Rewards. } \\
\text { Motivational and } \\
\text { reward issues offered } \\
\text { to professionals to } \\
\text { engage with the HIS. }\end{array}$ & $\begin{array}{l}\text { Organizational } \\
\text { Strategy. Relates } \\
\text { specifically to all } \\
\text { strategic } \\
\text { decisions made } \\
\text { for the adoption } \\
\text { of HIS. }\end{array}$ & $\begin{array}{l}\text { IT in use. Barriers that are } \\
\text { related to the proper, } \\
\text { effective, effortless and } \\
\text { costless use of a } \\
\text { home-based telemedicine } \\
\text { system when is put into } \\
\text { use and cannot be } \\
\text { associated with the } \\
\text { infrastructure or software } \\
\text { design }\end{array}$ \\
\hline $\begin{array}{l}\text { Autonomy } \\
\text { Relates to the impact } \\
\text { that HIS may have } \\
\text { on the autonomy } \\
\text { of the stakeholders }\end{array}$ & $\begin{array}{l}\text { Support. Relates to the } \\
\text { Organizational } \\
\text { support needed to } \\
\text { design or redesign } \\
\text { business processes. }\end{array}$ & $\begin{array}{l}\text { Change. Relates to the } \\
\text { changes that HIS } \\
\text { may bring to patients } \\
\text { and carers }\end{array}$ & $\begin{array}{l}\text { Change. Relates to the } \\
\text { changes that HIS } \\
\text { may bring to HC } \\
\text { professionals. } \\
\text { Liability and } \\
\text { accountability. } \\
\text { Relevant to liability } \\
\text { and accountability of } \\
\text { HC professionals } \\
\text { when engaging with } \\
\text { the HIS. }\end{array}$ & $\begin{array}{l}\text { Finance. Relates to } \\
\text { financial issues } \\
\text { derived from the } \\
\text { adoption of HIS. }\end{array}$ & $\begin{array}{l}\text { Results/Impact. Barriers } \\
\text { derived from the actual } \\
\text { impact that the HIS may } \\
\text { have on the organization. } \\
\text { Trust. Issues of trust and } \\
\text { confidence arising from } \\
\text { the use of the IT } \\
\text { infrastructure by the } \\
\text { intended users }\end{array}$ \\
\hline
\end{tabular}


Subsequently, the results were compared amongst the researchers, and when inconsistencies were found, these were discussed until a consensus was reached.

\section{Analysis of the Results}

In the following subsections, the barriers identified in this research work are presented and discussed. The barriers are organized into six categories according to the different perspectives derived from the study: Structure of $\boldsymbol{H C}$ Organizations, HC Organizational Processes, Patients and Carers, HC Professionals, Strategy and Information
Systems. To provide an idea of the strength of the evidence supporting the identification of each barrier, each perspective is mapped to the four groups of stakeholders, i.e., Controllers, Providers, Supporters, and Acceptors. Columns in Table 3 indicate each of the six perspectives and the rows indicates the stakeholders in each of the four groups. Each of the cells indicates the number of barriers identified in the corresponding perspective by the corresponding stakeholder.

\subsection{Overall Results}

The initial approach was to map the number of instances reported for each perspective by each group of stakeholders.

Table 3 Perceived number of barriers per stakeholder groups

\begin{tabular}{|c|c|c|c|c|c|c|c|}
\hline & $\begin{array}{l}\text { 1. Structure of HC } \\
\text { organisations }\end{array}$ & $\begin{array}{l}\text { 2. HC Organisational } \\
\text { processes }\end{array}$ & $\begin{array}{l}\text { 3. Patients and } \\
\text { carers }\end{array}$ & $\begin{array}{l}\text { 4. } \mathrm{HC} \\
\text { Professionals }\end{array}$ & 5. Strategy & $\begin{array}{l}\text { 6. Information } \\
\text { systems }\end{array}$ & Totals \\
\hline \multicolumn{8}{|l|}{ Controllers } \\
\hline Ethical approval committees & 2 & 1 & 1 & 4 & 2 & 9 & 19 \\
\hline General Health Authorities & 0 & 2 & 0 & 2 & 5 & 5 & 14 \\
\hline Medical Director & 0 & 1 & 0 & 3 & 5 & 4 & 13 \\
\hline Hospital Managers & 0 & 2 & 0 & 1 & 4 & 1 & 8 \\
\hline Project Leader & 0 & 0 & 0 & 3 & 2 & 3 & 8 \\
\hline Subtotals & 2 & 6 & 1 & 13 & 18 & 22 & 62 \\
\hline Weighted subtotals & 0.4 & 1.2 & 0.2 & 2.6 & 3.6 & 4.4 & 12.4 \\
\hline \multicolumn{8}{|l|}{ Providers } \\
\hline Home Support teams & 0 & 0 & 1 & 7 & 1 & 6 & 15 \\
\hline Specialist Dr. (2) & 1 & 0 & 1 & 2 & 3 & 9 & 16 \\
\hline Case Manager & 0 & 0 & 0 & 5 & 1 & 4 & 10 \\
\hline GP (2) & 0 & 1 & 0 & 0 & 3 & 6 & 10 \\
\hline Clinical Technicians & 0 & 0 & 0 & 3 & 2 & 3 & 8 \\
\hline Specialist Nurse (2) & 0 & 0 & 0 & 5 & 1 & 2 & 8 \\
\hline Call Center Assistant & 0 & 0 & 0 & 2 & 1 & 0 & 3 \\
\hline Subtotals & 1 & 1 & 2 & 24 & 12 & 30 & 70 \\
\hline Weighted subtotals & 0.1 & 0.1 & 0.2 & 2.4 & 1.2 & 3 & 7 \\
\hline \multicolumn{8}{|l|}{ Supporters } \\
\hline Industry (telecom/mobile) (3) & 2 & 4 & 2 & 8 & 7 & 10 & 33 \\
\hline IS Managers & 0 & 1 & 0 & 0 & 4 & 5 & 10 \\
\hline Hospital Researchers & 0 & 0 & 0 & 1 & 3 & 4 & 8 \\
\hline IT Specialist & 0 & 0 & 0 & 1 & 2 & 3 & 6 \\
\hline ERP system Managers & 1 & 1 & 1 & 3 & 2 & 10 & 18 \\
\hline University research teams (4) & 0 & 0 & 1 & 6 & 2 & 8 & 17 \\
\hline Subtotals & 3 & 6 & 4 & 19 & 20 & 40 & 92 \\
\hline Weighted subtotals & 0.27 & 0.55 & 0.36 & 1.73 & 1.82 & 3.64 & 8.36 \\
\hline \multicolumn{8}{|l|}{ Acceptors } \\
\hline Patients (7) & 0 & 0 & 0 & 0 & 0 & 3 & 3 \\
\hline Subtotals & 0 & 0 & 0 & 0 & 0 & 3 & 3 \\
\hline Weighted subtotals & 0.00 & 0.00 & 0.00 & 0.00 & 0.00 & 0.43 & 0.43 \\
\hline Grand Totals & 6 & 13 & 7 & 56 & 50 & 95 & 227 \\
\hline
\end{tabular}


This approach has the objective to identify those groups that perceive more barriers and the type of barriers they reported. The results are presented in the subtotal rows in Table 3.

The subtotal rows suggest that, in principle, Supporters reported more barriers than the other groups (92), followed by the Providers (70), and then the Controllers (62). Acceptors are the group that reported significantly fewer barriers than the other three groups (3).

Each of the stakeholder groups, however, has a different number of stakeholders. For example, The Providers group has seven sub-groups of stakeholders whereas the Controllers group has five. In addition to these differences, some subgroups have more participants than others. For instance, within the providers' group two specialist Doctors (clinicians), two GP and two Specialist Nurses were interviewed, whereas for the remaining subgroups only one member was interviewed (this is denoted in Table 3 as numbers next to the stakeholder names). This event implies that the groups with more participants will potentially produce more barriers; hence the comparison between groups could be flawed.

To have a uniform way to compare the barriers reported against the stakeholder groups, the number of barriers was weighted against the number of stakeholders in each group. For example, the subtotals in the Providers group were divided by 10 stakeholders (2 Specialist Doctors, 2 Specialist nurses, 2 GPs, and one member for each of the rest subgroups), whereas the Controllers were divided by five. This information is depicted in Table 3 in the "weighted subtotals" rows for each group. After weighing the subtotals, Controllers perceive more barriers, followed by the Supporters and then the Providers. The Acceptors remained as the group that reported considerably fewer barriers than the other groups.

\subsection{Results per Stakeholder Groups}

\subsubsection{The Acceptors Group}

The Acceptors group is composed of 7 individuals (patients). Acceptors are the group of stakeholders that, practically, does not find any barriers to the use and implementation of the HIS under investigation (only three). According to our data, Patients and Carers tend to be very positive about the use of these types of systems and can only perceive the benefits these may bring to their lives. Patients were even willing to share the cost of these new services; a factor that was analyzed in this research and it was, in principle, well accepted by the majority of patients (This study also collected benefits of HIS but are not included in this paper). This finding suggests that, in our case, the Acceptors group does not represent a significant resistance factor when trying to implement HIS when compared to the other groups. On the contrary, they are keen on testing new ways to improve the delivery of healthcare as long as they can see the benefits. This information may contradict what is found in the literature because there is evidence that suggests the Acceptors present more significant barriers. For example, King et al. describe "Lack of confidence, physical and intellectual skills were identified as barriers to using this technology" referring to the Acceptors group in general (King et al. 2011, p.357). It is not clear in the paper, however, which stakeholder group reported this barrier. We argued before that there are many stakeholders in HIS and that when a barrier is reported, it is relevant to know which stakeholder has reported it. For example, this research found a barrier reported as "Patients can have difficulties using the technology", which may be similar to the barrier found by King et al. In this case study, however, this barrier was not reported by the Acceptors (patients) but by all the other stakeholder groups. According to this study, one can imply that the Acceptors will not put much resistance when adopting HIS as long as the benefits are clearly explained. It also suggests that the other stakeholder groups need to adjust their perception of the Acceptors group, as the later does not appear to indicate that they will pose many barriers. Considering that Acceptors group reported very few barriers in this case study, the remaining analysis of the stakeholder's views will not include this group unless explicitly stated.

\subsection{The Controllers Group}

The Controllers group is represented by five individuals, each of them representing a subgroup: Ethical Approval Committees, General Health Authorities, Medical Director, Hospital Managers and Project Leader. In this group, three individuals (subgroups) identified more than $70 \%$ of the overall barriers of this group: Ethical Approval Committees, General Health Authorities, and Medical Director. The rest are distributed equally amongst Hospital Managers and Project Leader. The Ethical Approval Committee is formed by a group of hospital managers from different areas and has the responsibility for deciding if each study or project is ethically viable and that all the paperwork, such as information for patients, is prepared. They examine the protocols and the types of interventions that are going to be conducted to patients. Ethical approval is required before any project can start. The General Health Authorities have responsibility for the health system in their respective geographies. They define policies for the general provision of health care. Industry (telecom) funded this project during the pilot phase; however, when successful and included in the regular Healthcare services; the public Healthcare System will fund it.

The Controllers is the group that reported more barriers than the other three groups, with 12.4 barriers per person, while the other two groups are slightly below ( 7 and 8.3 per person). Considering that the Controllers group influences and governs, to some extent, the adoption of HIS systems, it makes sense that this group has more opinions about both 
barriers and benefits. It also suggests that this group is more aware of the benefits and barriers of HIS. The Controllers, like the other three groups, identified more barriers in the perspective of Information Systems. Within the Information Systems category the barrier that was most mentioned by the controllers (4 times reported -instances-) is shown below:

Too many actors involved, difficulties to align and coordinate all of them. A very fragmented system. Lack of tradition to work in collaboration. Organizations are very complex.

The second perspective, with considerably more barriers reported, is Strategy. Within the Strategy category the barriers that were most mentioned by the Controllers (3 instances) are shown below:

Lack of organizational culture to deal with these projects. Healthcare sector has not been considered as an Industry.

Lack of investment in the area, funding problems. High initial funding. Unclear situation about who has to pay, hospital or regional authorities.

The Strategy perspective, relates to all strategic decisions needed for the adoption of HIS systems, hence it is also natural they can identify more barriers in all the strategic decisions behind HIS systems.

\subsubsection{The Supporters Group}

The Supporters group help in the design and implementation of HIS. This group is the larger of all, represented by 11 individuals divided into six subgroups as follows: Industry with three individuals, University Research Teams with four individuals, and with one individual: IS managers, Hospital Researchers, IT specialists, and ERP system Managers.

The two subgroups that identified half of the barriers in this group are Telecom Companies and ERP Managers. ERP managers are part of the IS department and are responsible for the ERP information systems. Their responsibilities include maintaining and supporting the Information Systems of the hospital and the connections with any other Information Systems that could be used in the hospital. In this research, the ERP system is the core system of the hospital. The relevance of the ERP system within the hospital made it necessary to differentiate this group from the IS manager.

The Supporters group is directly concerned with the technology used to implement the HIS. Therefore it was expected that they reported considerably more barriers in the Information Systems category than any other barrier. Within this category the Supporters reported the next barrier more than any other (5 instances):

Lack of integration with hospital information systems. Lack of data integrity.

The results also show that the second category had more barriers reported by this group in the strategy category. Within this category the barrier that was most mentioned by the Supporters (7 instances) is shown below:

Lack of investment in the area, funding problems. High initial funding. Unclear situation about who has to pay, hospital or regional authorities.

\subsubsection{The Providers Group}

Finally, the providers' group is represented by ten individuals, divided into seven subgroups as follows: Specialist Doctors with two individuals, General Practitioners with two individuals, Specialists Nurses with two individuals, and with one individual each are: Home Support Teams, Case Manager, Clinical Technicians, and Call Center Assistant.

The Providers group reported fewer barriers than the other two large groups. The providers are the group of stakeholders that are part of the healthcare sector and provide healthcare services including HIS. These include GPs, specialist doctors, and nurses. As with other groups, they identified more barriers in the Information Systems category. Within this category the Providers reported the next barrier more than any other barrier (5 instances):

Too many actors involved, difficulties to align and coordinate all of them. A very fragmented system. Lack of tradition to work in collaboration. Organizations are very complex.

A second category where barriers are reported is the Healthcare Professionals category, which was expected as this category relates specifically to them. Within this category, the Providers reported the following barrier more than any other (4 instances)

Change Resistance in some healthcare professionals.

\subsection{Analysis per Barrier's Category}

The total of instances reported in this study were 227. In other words, the 33 participants of this study reported 277 barriers. Three out of the six categories represent most of the total of instances reported (89\%): HC Professionals with $24 \%$ of the 
instances, Strategy with $22 \%$ and Information Systems (the highest) with $43 \%$. These three categories are analyzed in more detail in the following sections.

\subsubsection{HC Professionals Category}

The total number of instances reported in this category was 56 grouped into 13 barriers. This first observation is that some barriers are reported by all stakeholders, while others are not. This finding suggests that some barriers are not visible or that can only be perceived by some groups, and there are others that have consensus amongst all the stakeholders, and hence can be perceived to be more relevant.

Table 4 shows the most relevant barriers in this category. The criteria used to define the most relevant barriers was to select those that are reported at least once by all three groups of stakeholders (excluding acceptors), and that is equal or above the average number of instances per barrier. For example, the HC Professionals category identified 13 barriers. The total number of instances supporting all 13 barriers is 56 .
Thus, the average number of instances per barrier in this category is 4.

The barrier that was mentioned by far in more instances by all groups is "Change resistance in some healthcare professionals". This last barrier shows a consensus amongst all participant groups and is mentioned 12 times by several stakeholders. This information corroborates other findings such as Shakshuki and Khalifa (2013) and Moffatt and Eley (2011). The main difference in our findings and other research is that the reader is aware that all stakeholders found this barrier to be important; hence it is somehow more relevant than other barriers. For example, another barrier that was found in our research is "Lack of financial reward to healthcare participants" and is also supported in the literature (Hill and Powell 2009; Moffatt and Eley 2011; Lluch 2011). In our research, however, this barrier was not supported by all groups of stakeholders, and it was reported only three times. Following our exclusion criteria, this barrier is perceived to be less relevant than other barriers and was excluded from Table 4.
Table 4 Barriers reported in the HC professionals category

\begin{tabular}{|c|c|c|c|c|c|c|}
\hline \multicolumn{7}{|c|}{ HC Professionals category } \\
\hline Barriers & Subcategory & Supporters & Providers & Controllers & Acceptors & Totals \\
\hline $\begin{array}{l}\text { Lack of training for } \\
\text { professionals. } \\
\text { Professionals are } \\
\text { not trained in new } \\
\text { technologies }\end{array}$ & Training & 1 & 2 & 2 & 0 & 5 \\
\hline $\begin{array}{l}\text { Lack of awareness } \\
\text { about the potential } \\
\text { use of } \\
\text { telemedicine }\end{array}$ & HC-IT knowledge & 2 & 1 & 10 & 4 & \\
\hline $\begin{array}{l}\text { Demands unpaid } \\
\text { extra time for } \\
\text { health } \\
\text { professionals }\end{array}$ & Motivation/Rewards & 2 & 3 & 1 & 0 & 6 \\
\hline $\begin{array}{l}\text { Increase the } \\
\text { workload. Have } \\
\text { more active } \\
\text { patients. }\end{array}$ & Motivation/Rewards & 2 & 3 & 1 & 0 & 6 \\
\hline $\begin{array}{l}\text { Involvement and } \\
\text { motivation of } \\
\text { healthcare } \\
\text { professionals is } \\
\text { low }\end{array}$ & Motivation/Rewards & 1 & 2 & 1 & 0 & 4 \\
\hline $\begin{array}{l}\text { Change Resistance in } \\
\text { some healthcare } \\
\text { professionals. } \\
\text { Nurses and } \\
\text { primary care } \\
\text { doctors }\end{array}$ & Change & 5 & 4 & 3 & 0 & 12 \\
\hline $\begin{array}{l}\text { Healthcare } \\
\text { professionals are } \\
\text { not used to } \\
\text { different ways of } \\
\text { working. }\end{array}$ & Change & 2 & 2 & 3 & 0 & 7 \\
\hline
\end{tabular}




\subsubsection{HC Professionals Category Verification}

During the verification phase, the barriers perceived more relevant were presented for verification purposes to a different group of stakeholders (see Table 5). The information included in this table consist of the level of the agreement obtained from the groups taking part in the feedback second round. The values presented go from (1 - Fully Disagreement to 5 - Fully Agreement). In general terms, the barriers previously identified were confirmed. The barriers having a higher level of confirmation were related to the lack of awareness about the potential use of telemedicine and the unpaid extra time demanded for the health professional to manage correctly the systems and the information obtained. The barriers having less confirmation were those related to the training subcategory.

\subsubsection{Strategy Category}

The total number of instances reported in this category was 50 grouped into 15 barriers. The Supporters represent $40 \%$ of all instances, followed by the Controllers (36\%) and lastly by the Providers with $24 \%$ of all instances reported in this category. A closer analysis of the subcategories in this category shows that from a total of 15 barriers reported; only two barriers were reported by all stakeholders (except the acceptors) - these are shown in Table 6. The lack of investment in the HIS sector and the fuzziness of the financial aspects of these types of projects were significantly reported by all three groups and is also supported in the literature (Moffatt and Eley 2011).

The second barrier reported related to Organizational culture and is also supported in the literature (Lluch 2011). These barriers are due to the difficulties in changing the Organizational culture. Traditionally, there is a reluctance to changing well-established processes, especially in the healthcare sector (Moffatt and Eley 2011; Shakshuki and Khalifa 2013). Therefore, introducing new technologies for monitoring and treatment of chronically ill patients, and consequently introducing new processes in the clinical pathway, is expected to cause resistance from all affected stakeholders.
Table 5 HC professionals category verification results

\begin{tabular}{|c|c|c|c|c|c|c|}
\hline \multicolumn{7}{|c|}{ HC Professionals category } \\
\hline Barriers & Subcategory & Supporters & Providers & Controllers & Acceptors & Totals \\
\hline $\begin{array}{l}\text { Change Resistance in } \\
\text { some healthcare } \\
\text { professionals. } \\
\text { Nurses and } \\
\text { primary care } \\
\text { doctors }\end{array}$ & Change & 4.43 & 3.82 & 4.20 & 3.43 & 3.93 \\
\hline $\begin{array}{l}\text { Healthcare } \\
\text { professionals are } \\
\text { not used to } \\
\text { different ways of } \\
\text { working. }\end{array}$ & Change & 4.00 & 3.73 & 4.00 & 4.00 & 3.82 \\
\hline $\begin{array}{l}\text { Lack of awareness } \\
\text { about the potential } \\
\text { use of } \\
\text { telemedicine }\end{array}$ & HC-IT Knowledge & 3.71 & 4.45 & 4.00 & 4.00 & 4.10 \\
\hline $\begin{array}{l}\text { Demands unpaid } \\
\text { extra time for } \\
\text { health } \\
\text { professionals }\end{array}$ & Motivation/Rewards & 3.57 & 4.55 & 4.40 & 4.43 & 4.27 \\
\hline $\begin{array}{l}\text { Increase the } \\
\text { workload. Have } \\
\text { more active } \\
\text { patients. }\end{array}$ & Motivation/Rewards & 3.57 & 3.36 & 3.00 & 4.43 & 3.60 \\
\hline $\begin{array}{l}\text { Involvement and } \\
\text { motivation of } \\
\text { healthcare } \\
\text { professionals is } \\
\text { low }\end{array}$ & Motivation/Rewards & 3.57 & 3.36 & 4.20 & 4.00 & 3.67 \\
\hline $\begin{array}{l}\text { Lack of training for } \\
\text { professionals. } \\
\text { Professionals are } \\
\text { not trained in new } \\
\text { technologies }\end{array}$ & Training & 3.86 & 3.64 & 3.00 & 3.29 & 3.50 \\
\hline
\end{tabular}


Table 6 Barriers reported in the strategy category

\begin{tabular}{lllllll}
\hline Strategy Category & & & & & \\
\hline Barriers & Subcategory & Supporters & Providers & Controllers & Acceptors & Totals \\
\hline $\begin{array}{l}\text { Lack of organisational to } \\
\text { deal culture with these } \\
\text { projects. Healthcare }\end{array}$ & $\begin{array}{c}\text { Organisational } \\
\text { Culture }\end{array}$ & 2 & 1 & 3 & 0 & 6 \\
$\begin{array}{l}\text { sector has not been } \\
\text { consider as an industry }\end{array}$ & & & & & \\
$\begin{array}{l}\text { Lack of investment in the } \\
\text { area, funding problems. }\end{array}$ & Finance & 7 & 6 & 3 & 0 & 16 \\
$\begin{array}{l}\text { High initial funding. } \\
\begin{array}{l}\text { Unclear situation about } \\
\text { who has to pay, } \\
\text { hospital or regional }\end{array}\end{array}$ & & & & & \\
authorities. & & & & & \\
\hline
\end{tabular}

\subsubsection{Strategy Category Verification}

During the results verification phase, the barriers perceived more relevant were presented to a different group of stakeholders (see Table 7). In general terms, the barriers previously identified were confirmed. An interesting observation is that that the organizational culture barrier is less perceived by supporters and acceptors. A probably cause is due to these two groups are not quite aware of the organization's internal processes related to the monitoring of patients having chronic diseases.

\subsubsection{Information Systems Category}

The total number of instances reported in this category was 95 grouped into 27 barriers. The average of instances per barrier is 4 . The Supporters group reported most of the total of instances with $42 \%$ of them, followed by the Providers with $32 \%$, then the Controllers with $23 \%$, and finally the Acceptors with $3 \%$. The fact this category contains most of the barriers can be explained by looking at the way this category was defined and its context in this research.
The Information Systems (IS) category aims to capture the barriers arising from the design and implementation of software/IT, and from the actual use of the HIS by the intended users. This category is based on Paul's definition of Information Systems (Paul 2010b). Paul starts by distinguishing IS from Information Technology (IT). IT, he argues, is a collection of devices, software and accessories, which when combined might provide a part, or all of the delivery mechanism for any IS that uses this mechanism. The IS is what emerges from the usage that is made of the IT delivery system by the users. This usage will be made up of two parts:

1. The formal processes, which are assumed to be predeterminable and are usually supported by the IT.

2. The informal processes, which are what the human beings who use the IT and the formal processes created or invented to ensure that useful work is done.

The Information System, then, is what "emerges" from the use of technology and the formal and informal processes by all its users.
Table 7 Strategy category verification results

\begin{tabular}{|c|c|c|c|c|c|c|}
\hline \multicolumn{7}{|l|}{ Strategy Category } \\
\hline Barriers & Subcategory & Supporters & Providers & Controllers & Acceptors & Totals \\
\hline $\begin{array}{l}\text { Lack of investment in the } \\
\text { area, funding problems. } \\
\text { High initial funding. } \\
\text { Unclear situation about } \\
\text { who has to pay, } \\
\text { hospital or regional } \\
\text { authorities. }\end{array}$ & Finance & 4.10 & 4.33 & 4.00 & 4.00 & 4.14 \\
\hline $\begin{array}{l}\text { Lack of organisational to } \\
\text { deal culture with these } \\
\text { projects. Healthcare } \\
\text { sector has not been } \\
\text { consider as an industry }\end{array}$ & $\begin{array}{l}\text { Organisational } \\
\text { Culture }\end{array}$ & 3.79 & 4.23 & 4.30 & 3.50 & 4.06 \\
\hline
\end{tabular}


The classification of this category, thus, started by differentiating those issues that are related to the technology itself from those categories that are related to the use of the information system. This division resulted in having two subcategories related to the technology (IT Infrastructure and Software Design) and three subcategories related to its use (IT in use, Results/Impact, and Trust). A closer look at the barriers in this category showed that only $4 \%$ of all instances relate to IT infrastructure and $17 \%$ relate to software design issues. This finding means that the barriers related to the technology itself represent only $21 \%$ of the total of instances in this category. On the other hand, $43 \%$ of the barriers in this category relate to issues of technology use, or the emergent IS, $22 \%$ to results/impact and $14 \%$ to trust. All three nontechnical aspects represent $79 \%$ of the barriers in this category. These results suggest that there is a certain degree of maturity of the technology used in HIS and that most of the problems related to IT in these types of systems are due to managerial and social aspects of using the technology. Table 8 corroborates the previous statement and shows that the barrier that has more instances reported by all stakeholders (but Acceptors) is within the "IT in use" category and is related to the complexity of the healthcare Organizations and a large number of stakeholders. This barrier was also found in the literature (Roig and Saigí 2011; Lluch 2011).

All barriers presented in Table 8 have been found in the literature apart from "Lack of robust commercial solutions. Technology is still immature (Prototypes not fully reliable and operative, do not reflect all the functionality needed)". In contrast, the barriers listed below were found in this research and are also reported in the literature but are not included in Table 8 because all group of stakeholders does not support them, and the frequency of instances per barrier was lower than the average.

- "Need of integrated information about the patient. Lack of integrated electronic patient record" (Shakshuki and Khalifa 2013)

- "Lack of tradition in the use of technology by healthcare professionals" (Hjelm 2005)

- "Telecommunication and Technology industry do not understand the medical business (regulation problem)" (Hjelm 2005)

- "Projects need to demonstrate that are cost-effective and that increase quality of life. It is needed larger pilots projects" (Currie and Seddon 2014)

- "Concerns about data security, privacy and accuracy" (Hjelm 2005)

\subsubsection{Information Systems Category Verification}

In general terms, the barriers previously identified were confirmed during the verification phase (see Table 9). The barrier "Healthcare professionals tend to be reluctant about technology", however, had some discrepancies in this second
Table 8 Barriers reported in the information systems category

\begin{tabular}{|c|c|c|c|c|c|c|}
\hline \multicolumn{7}{|l|}{ HC Professionals Category } \\
\hline Barriers & Subcategory & Supporters & Providers & Controllers & Acceptors & Totals \\
\hline $\begin{array}{l}\text { Lack of integration with } \\
\text { hospital information } \\
\text { systems. Lack of data } \\
\text { integrity }\end{array}$ & $\begin{array}{l}\text { Software } \\
\text { Design }\end{array}$ & 5 & 3 & 2 & 0 & 10 \\
\hline $\begin{array}{l}\text { Too many actors involved, } \\
\text { difficulties to align and } \\
\text { coordinate all of them. A } \\
\text { very fragmented system. } \\
\text { Lack of tradition to work } \\
\text { in collaboration. } \\
\text { Organisations are very } \\
\text { complex. }\end{array}$ & IT in use & 3 & 5 & 4 & 0 & 12 \\
\hline $\begin{array}{l}\text { Lack of robust commercial } \\
\text { solutions. Technology is } \\
\text { still immature } \\
\text { (Prototypes not fully } \\
\text { reliable and operative, } \\
\text { do not reflect all the } \\
\text { functionality needed) }\end{array}$ & IT in use & 3 & 3 & 1 & 0 & 7 \\
\hline The area is still emergent & Resultslimpact & 4 & 3 & 2 & 0 & 9 \\
\hline $\begin{array}{l}\text { Healthcare professionals } \\
\text { tend to be reluctant } \\
\text { about technology }\end{array}$ & Trust & 2 & 2 & 3 & 0 & 7 \\
\hline
\end{tabular}


Table 9 Information systems category verification results

\begin{tabular}{|c|c|c|c|c|c|c|}
\hline Barriers & Subcategory & Supporters & Providers & Controllers & Acceptors & Totals \\
\hline $\begin{array}{l}\text { Too many actors involved, } \\
\text { difficulties to align and } \\
\text { coordinate all of them. A } \\
\text { very fragmented system. } \\
\text { Lack of tradition to work } \\
\text { in collaboration. } \\
\text { Organisations are very } \\
\text { complex. }\end{array}$ & IT in use & 4.29 & 4.50 & 4.40 & 4.40 & 4.43 \\
\hline $\begin{array}{l}\text { Lack of robust commercial } \\
\text { solutions. Technology is } \\
\text { still immature } \\
\text { (Prototypes not fully } \\
\text { reliable and operative, } \\
\text { do not reflect all the } \\
\text { functionality needed) }\end{array}$ & IT in use & 4.71 & 4.63 & 4.60 & 4.60 & 4.59 \\
\hline The area is still emergent & Resultslimpact & 3.43 & 4.75 & 3.20 & 3.20 & 4.11 \\
\hline $\begin{array}{l}\text { Lack of integration with } \\
\text { hospital information } \\
\text { systems. Lack of data } \\
\text { integrity }\end{array}$ & $\begin{array}{l}\text { Software } \\
\text { Design }\end{array}$ & 4.71 & 4.73 & 5.00 & 4.46 & 4.72 \\
\hline $\begin{array}{l}\text { Healthcare professionals } \\
\text { tend to be reluctant } \\
\text { about technology }\end{array}$ & Trust & 3.71 & 3.27 & 3.40 & 3.40 & 3.47 \\
\hline
\end{tabular}

stage so that it can be considered is less important than initially thought. Similarly, the barrier "The area is still emergent" had fewer agreements in the case of controllers, suppliers and acceptors. The probable cause of this variation might be the controllers and suppliers interviewed have been involved in innovation and research projects for many years. They had the impression that the actual state of technology is not so emergent, but the solutions provided did not achieve the appropriate level of maturity. In the case of acceptors, they know the actual offer of Apps for smartphones to support a healthy life. Nevertheless, they were not so aware that several chronic diseases that need another kind of technologies that are not used widely in hospital attention contexts.

\section{Conclusions}

This article claims that by offering a more detailed view of the relationship that exists between the different stakeholder groups involved in HIS and the barriers reported by those groups, helps to provide a better understanding of the nature of the barriers that need to be surmounted. This picture also helps in the identification of the stakeholder groups that need to be involved in overcoming each of the barriers. The analysis of the results presented in previous sections helped to support this argument. For instance, it was found that there are groups of stakeholders that tend to have more opinions than others, a situation that may skew the results of the study towards the stronger stakeholder groups. In our study, it was found that the Controllers had $44 \%$ of the total number of instances reported (weighted), a situation that may suggest that the results could be inclined towards this particular group of stakeholders. To avoid this issue, the barriers that were reported at the end of this study were those where all group of stakeholders coincide at least once. This approach also uncovered the relevance a particular barrier may have and possibly its priority. For example, in this study "Lack of investment in the area/ funding problems" was the barrier that was reported the most by all three different groups (16 instances). Hence it could indicate its relevance when compared to the others. This result was corroborated by current literature as the same barrier is identified by different authors (Moffatt and Eley 2011; Roig and Saigí 2011). Table 10 shows all the barriers where all stakeholders coincide in order of relevance (instances reported).

The analysis also showed that there are other barriers reported in the literature (and also in our case study) where the number of instances reported was much lower than others, and more importantly, not all the stakeholders coincide with the same view. For example, the barrier "Projects need to demonstrate that are cost-effective and that increase quality of life" was found in our study and also supported by the literature (Currie and Seddon 2014). Only one stakeholder "University Research Teams" within the Supporters group, however, mentioned this barrier. For this reason, it was not included in the final list. These results support the view that the way of 


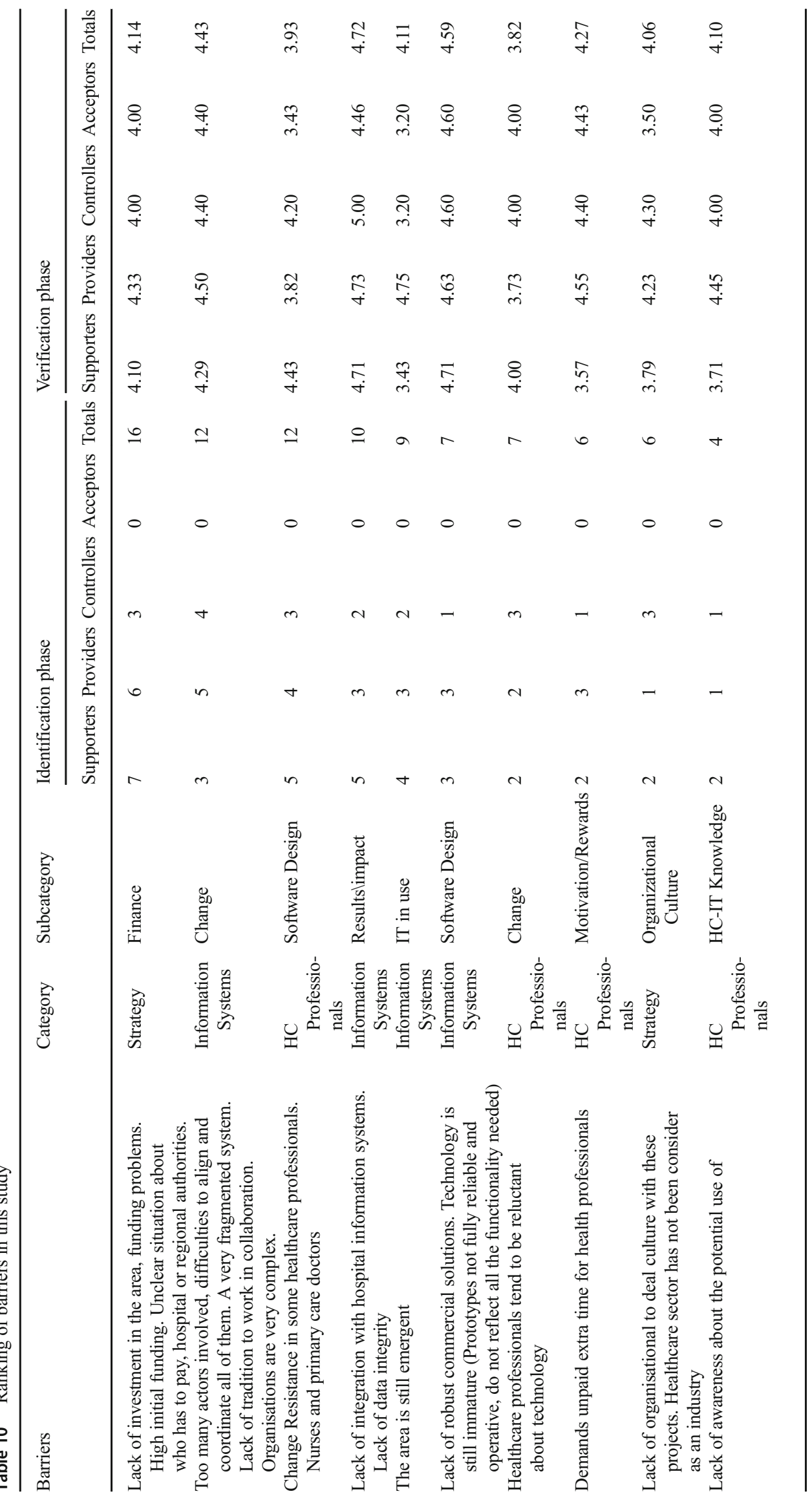


presenting barriers without any other information may not be enough to understand the relevance that these may have for all stakeholders involved. It is evident that some barriers will be mentioned by a particular group with a particular view and thus may not have the broader relevance as barriers where all groups coincide.

Our study also concludes that the group of Acceptors presented only a couple of barriers, which suggests they are willing to adopt these kinds of systems. It also suggests that the Acceptors group may not be aware of the strategy, Information Systems and organizational barriers that make the adoption of this kind of solution more difficult than perceived by the society. The fact that the controllers found more barriers than any of the two groups (43\%) followed by the Supporters $(29 \%)$ suggest that the challenge of HIS today lies in the coordination and implementation rather than the acceptance of the other groups (Providers and Acceptors). Within the top 10 Barriers identified by all stakeholder groups (see Table 10) only one can be related to the technology itself, and the rest are related to the impact that the implementation of HIS has on the organization and stakeholders involved.

The analysis of the barriers per category also showed that three out of the six categories used to classify the barriers represent most of the total of instances reported in this study (89\%): HC Professionals with $24 \%$ of the instances, Strategy with $22 \%$ and Information Systems (the highest) with $43 \%$. Moreover, most of the barriers found in the IS category are barely related to problems with the technology, but with the use of technology by the stakeholders. The complexity of such systems is one of the leading problems, although unsurprisingly this problem is not concerned only with HIS, but to the wider IS domain.

\section{Final Reflections}

The analysis and contextualization of the barriers in this study have enabled the authors to report on several implications from this research work. The first and most important implication is that, despite the possible barriers, HIS can be proved beneficial in improving the quality of life for patients with chronic conditions and in providing better control of the evolution of their diseases. Indeed, all the patients involved in the projects felt more secure and had better control of their condition when using the system than without it. To progress in this field; however, several challenges need to be surmounted. For instance, finance comes as the most relevant barrier reported in our study and supported by other literature. The findings suggest that it is likely that a new economic and organizational model is needed to adopt HIS into mainstream healthcare services. It reflects the need to find the return of investment in HIS and the possible sources of investment. Are the HIS good investments? How should it be assessed? More studies are needed to find out, for example, if the hospitalization costs derived from the lack of proper monitoring could be factored in the return of investment. New models could also take into account the possibility of sharing the cost of these new services with the patient, a factor that was analyzed in this research and, in principle, was well accepted by the majority of patients.

Another implication to be considered is the resistance to change from the stakeholders, particularly with the providers. The Providers group rated the barrier "Change Resistance in some healthcare professionals" more than any other barrier. The incorporation of new HIS usually requires to change workloads or assumes that less contacting time with patients is required. In addition, it may also develop new ways of tracking people having chronic diseases. These changes add more complexities to the adaptation of these types of systems into the mainstream. Previous studies also suggest that more investigation is needed to understand better the social structures in HIS adoption, more specifically a better understanding of the rules and division of labor of users or stakeholders groups such as the Acceptors and Providers who are the ultimate users of HIS (Sun and Qu 2014). Perhaps, IS developers need to use user-centered techniques that are more focused on the users (e.g. providers and acceptors) than on processes. Finally, the informal and formal relationships among professionals are essential issues. Power, politics and human relationships are as important here as in any other setting. Considering the number of different Organizations involved and the political repercussion that healthcare decisions have on citizens, these issues need to be carefully considered when deploying healthcare information systems.

Open Access This article is distributed under the terms of the Creative Commons Attribution 4.0 International License (http:// creativecommons.org/licenses/by/4.0/), which permits unrestricted use, distribution, and reproduction in any medium, provided you give appropriate credit to the original author(s) and the source, provide a link to the Creative Commons license, and indicate if changes were made.

\section{References}

Ammenwerth, E., Gräber, S., Herrmann, G., Bürkle, T., \& König, J. (2003). Evaluation of health information systems-problems and challenges. International Journal of Medical Informatics, 71, 125135.

Barbarito, F. et al. (2015). Implementing the lifelong personal health record in a regionalised health information system: The case of Lombardy, Italy. Computers in Biology and Medicine, 59, pp. 164-174. Available at: http://www.sciencedirect.com/science/ article/pii/S0010482513003089. Accessed 12 Apr 2017.

Chapman, K. R. P. \& Arunatileka, S. M. K. D. (2010). Teleconsultation Roadmap - The path to telemedicine. In 12th IEEE International Conference on e-Health Networking, Application and Services, Healthcom 2010. 
Cheng, J., Montalto, M., \& Leff, B. (2009). Hospital at home. Clinics in Geriatric Medicine, 25, 79-91.

Currie, W. L., \& Seddon, J. J. M. (2014). A cross-national analysis of eHealth in the European Union: Some policy and research directions. Information \& Management, 51(6), 783-797 Available at: http://www.sciencedirect.com/science/article/pii/ S0378720614000536. Accessed 12 Apr 2017.

De Vries, J. (2011). The shaping of inventory systems in health services: a stakeholder analysis. International Journal of Production Economics, 133, 60-69.

Duplaga, M., \& Zielinsky, K. (2006). Evolution of IT-enhanced healthcare: From telemedicine to e-health. In K. Zielinski, M. Duplaga, \& D. Ingram (Eds.), Information technology solutions for healthcare (pp. 1-21). London: Springer Verlag.

Eron, L. (2010). Telemedicine: the future of outpatient therapy? Clinical Infectious Diseases : an Official Publication of the Infectious Diseases Society of America, 51(Suppl 2), S224-S230.

Fitzgerald, G., Piris, L. \& Serrano, A. (2008). Identification of benefits and barriers for the adoption of e-health information systems using a sociotechnical approach. In Proceedings of the International Conference on Information Technology Interfaces, ITI. pp. 601-606.

Gagnon, M. P., Pluye, P., Desmartis, M., Car, J., Pagliari, C., Labrecque, M., Frémont, P., Gagnon, J., Njoya, M., \& Légaré, F. (2010). A systematic review of interventions promoting clinical information retrieval technology (CIRT) adoption by healthcare professionals. International Journal of Medical Informatics, 79, 669-680.

Goldkuhl, G. (2012). Pragmatism vs interpretivism in qualitative information systems research. European Journal of Information Systems, 21(2), 135-146. https://doi.org/10.1057/ejis.2011.54.

Gruber, H. G., Wolf, B. \& Reiher, M. (2009). Innovation barriers for telemonitoring. In IFMBE Proceedings. pp. 48-50.

Hebert, M. A., \& Korabek, B. (2004). Stakeholder readiness for telehomecare: implications for implementation. Telemedicine Journal and E-Health: the Official Journal of the American Telemedicine Association, 10, 85-92.

Helena, R. (2016). Cross-border healthcare directive: assessing stakeholders' perspectives in Poland and Portugal. Health Policy, 120(4), 369-376 Available at: http://www.sciencedirect.com/ science/article/pii/S0168851016300276. Accessed 12 Apr 2017.

Hersh, W., Helfand, M., Wallace, J., Kraemer, D., Patterson, P., Shapiro, S., \& Greenlick, M. (2002). A systematic review of the efficacy of telemedicine for making diagnostic and management decisions. Journal of Telemedicine and Telecare, 8, 197-209.

Hill, J. W., \& Powell, P. (2009). The national healthcare crisis: is eHealth a key solution? Business Horizons, 52, 265-277.

Hjelm, N. M. (2005). Benefits and drawbacks of telemedicine. Journal of Telemedicine and Telecare, 11, 60-70.

Hoerbst, A., Kohl, C. D., Knaup, P., \& Ammenwerth, E. (2010). Attitudes and behaviors related to the introduction of electronic health records among Austrian and German citizens. International Journal of Medical Informatics, 79, 81-89.

Holden, R. J., \& Karsh, B.-T. (2010). The technology acceptance model: its past and its future in health care. Journal of Biomedical Informatics, 43, 159-172.

Khatri, V. et al. (2011). A review of telemedicine services in Finland. In IFMBE Proceedings. pp. 1-8.

King, G., Heaney, D. J., Boddy, D., O’Donnell, C. A., Clark, J. S., \& Mair, F. S. (2011). Exploring public perspectives on e-health: findings from two citizen juries. Health Expectations, 14, 351-360.

Kivinen, T., \& Lammintakanen, J. (2013). The success of a management information system in health care - a case study from Finland. International Journal of Medical Informatics, 82(2), 90-97 Available at: http://www.ncbi.nlm.nih.gov/pubmed/22705086. Accessed 12 Apr 2017.

Koch, S. (2006). Home telehealth-current state and future trends. International Journal of Medical Informatics, 75, 565-576.
Lluch, M. (2011). Healthcare professionals' organizational barriers to health information technologies-a literature review. International Journal of Medical Informatics, 80(12), 849-862.

Lyons, S. S., Tripp-Reimer, T., Sorofman, B. A., Dewitt, J. E., Bootsmiller, B. J., Vaughn, T. E., \& Doebbeling, B. N. (2005). Information technology for clinical guideline implementation: perceptions of multidisciplinary stakeholders. Journal of the American Medical Informatics Association, 12, 64-71.

Mantzana, V., et al. (2007). Identifying healthcare actors involved in the adoption of information systems. European Journal of Information Systems, 16(1), 91-102 Available at: http://www.palgrave-journals. com/doifinder/10.1057/palgrave.ejis.3000660. Accessed 24 Apr 2017.

Martínez Álvarez, M., Chanda, R., \& Smith, R. D. (2011). How is telemedicine perceived? A qualitative study of perspectives from the UK and India. Globalization and Health, 7, 17.

Massoudi, B. L., et al. (2016). Using health information exchanges to calculate clinical quality measures: a study of barriers and facilitators. Healthcare, 4(2), 104-108 Available at: http://www.ncbi.nlm. nih.gov/pubmed/27343159. Accessed 12 Apr 2017.

May, C. R., Finch, T. L., Cornford, J., Exley, C., Gately, C., Kirk, S., Jenkings, K. N., Osbourne, J., Robinson, A. L., Rogers, A., Wilson, R., \& Mair, F. S. (2011). Integrating telecare for chronic disease management in the community: what needs to be done? BMC Health Services Research, 11, 131.

Moffatt, J. J., \& Eley, D. S. (2011). Barriers to the up-take of telemedicine in Australia - a view from providers. Rural and Remote Health, 11.

Paré, G., Raymond, L. \& de Guinea, A. (2014). Barriers to organizational adoption of EMR systems in family physician practices: a mixedmethods study in Canada. International journal of. Available at: http://www.sciencedirect.com/science/article/pii/ S138650561400104X. Accessed 12 Apr 2017.

Paul, R. J. (2010a). Loose change. European Journal of Information Systems, 19(4), 379-381. https://doi.org/10.1057/ejis.2010.40.

Paul, R. J. (2010b). What an information system is, and why is it important to know this. Journal of Computing and Information Technology, 18, 95-99.

Polisena, J., Tran, K., Cimon, K., Hutton, B., McGill, S., Palmer, K., \& Scott, R. E. (2010). Home telemonitoring for congestive heart failure: a systematic review and meta-analysis. Journal of Telemedicine and Telecare, 16, 68-76.

Pouloudi, A. (1999). Aspects of the stakeholder concept and their implications for information systems development. Proceedings of the 32nd Annual Hawaii International Conference on Systems Sciences 1999 HICSS32 Abstracts and CDROM of Full Papers, 0 (c), pp. 1-17. Available at: http://ieeexplore.ieee.org/lpdocs/ epic03/wrapper.htm?arnumber=772776.

Pouloudi, A., \& Whitley, E. A. (1997). Stakeholder identification in interorganizational systems: gaining insights for drug use management systems. European Journal of Information Systems, 6(1), 1-14 Available at: http://www.palgrave-journals.com/ejis/index.html.

Roig, F., \& Saigí, F. (2011). Facilitators in the implantation of telemedicine services. Perspective of professionals involved in its design and implementation [Elementos facilitadores en la implantación de servicios de telemedicina. Perspectiva de los profesionales implicados en su d]. Anales del Sistema Sanitario de Navarra, 34(2), 235-244 Available at: http://www.scopus.com/inward/ record.url?eid=2-s2.0-84856016374\&partnerID=40\&md5= $8 \mathrm{e} 0 \mathrm{e} 99$ eeaa6697d6041705068efld735.

Saleem, J. J., et al. (2015). Understanding barriers and facilitators to the use of clinical information systems for intensive care units and anesthesia record keeping: a rapid ethnography. International Journal of Medical Informatics, 84(7), 500-511 Available at: http://www. ncbi.nlm.nih.gov/pubmed/25843931. Accessed 12 Apr 2017.

Shakshuki, E., \& Khalifa, M. (2013). Barriers to health information systems and electronic medical records implementation. A field study of Saudi Arabian hospitals. Procedia Computer Science, 21, 335- 
342 Available at: http://www.sciencedirect.com/science/article/pii/ S1877050913008375.

Sun, J., \& Qu, Z. (2014). Understanding health information technology adoption: a synthesis of literature from an activity perspective. Information Systems Frontiers, 17(5), 1177-1190.

Vos, J. F. J., \& Achterkamp, M. C. (2006). Stakeholder identification in innovation projects: going beyond classification. European Journal of Innovation Management, 9, 161-178.

Walsham, G. (2006). Doing interpretive research. European Journal of Information Systems, 15(3), 320-330.

Williams, T., May, C., Mair, F., Mort, M., \& Gask, L. (2003). Normative models of health technology assessment and the social production of evidence about telehealth care. Health Policy (Amsterdam, Netherlands), 64(1), 39-54.

Yin, R. K. (2009). Case study research: Design and methods L. Bickman \& D. J. Rog, eds., Sage Publications. Available at: http://books. google.com/books?id=FzawIAdilHkC\&pgis $=1$.

Yusof, M. M., Paul, R. J. \& Stergioulas, L. K. (2006). Towards a Framework for Health Information Systems Evaluation. Proceedings of the 39th Annual Hawaii International Conference on System Sciences (HICSS'06), 5.

Dr Alan Serrano is a Senior Lecturer in the Department of Computer Science at Brunel University London, UK, where he also received his $\mathrm{PhD}$ in Information Systems and an MSc in Data Communication Systems. Previous to his appointment at Brunel he has worked in industry and public sectors in Mexico for many years, in the areas of computer networks and information systems development. His research interest lies in the area of digital strategy. More specifically, Dr Serrano focuses on undertaking research that aims to solve the real-life challenges organisations face when adopting information and communication technologies (ICT) in complex environments. Some examples of collaboration with industry include the automotive industry, Banking and Insurance sector, and the National Health Service (NHS). Dr Serrano has contributed to more than 26 publications in recognised international conferences and journals.
Javier García Guzmán is $\mathrm{PhD}$ in Computer Science by Carlos III University of Madrid (2001).He has 21 years of experience as a researcher and consultant in public and privatecompanies. Dr Garcia Guzmán has participated in several research projects related to open,and user-driven innovation approaches for software services, collaborative workingenvironments, smart cities and e-learning technologies (e.g., DAVINCI; Collaboration@Rural,Living Labs for e-health and social inclusion - CISVI, Mediterranean Living Labs - Medlab).He has published several books and international scientific papers related to living labs,software engineering, and collaborative working environments. As a result of this activity,Javier has been the Coordinator of the National Network of Social Spaces of Innovation andLiving Labs. He has also been Evaluator Living Labs the fourth and fifth wave of recognitionof Living Labs promoted by the European Network of Living Labs (ENoLL). He is SeniorResearcher at Software Engineering Lab coordinating linked open data, Mobile apps and elearningresearch unit and works on a part-time basis for coordinating the R\&D activities in the same area.

Dr Georgios Xydopoulos holds a PhD in Health Economics, Masters in Finance and Degree inBusiness Administration. He is an analytical researcher, with experience of working onresearch projects at high profile Institutions (Brunel University, Surrey University, Universityof East Anglia, MIT) and published in a number of journal outlets. Georgios specialises in theeconomic evaluation of healthcare information technology and the return on investment offered by online medical services.

Dr Ali Tarhini is an Assistant Professor at the College of Economics and Political Science,Information Systems Department, Sultan Qaboos University. He holds a PhD in InformationSystems from Brunel University London, UK, and MSc in E-commerce from University ofEssex, UK. His research interests include Big Data, Cloud Computing, IoT, KnowledgeManagement, Social Media, ICT in information systems (Technology adoption and diffusion),cross-cultural issues in IS (at an individual and national culture, cross-cultural studies). Alihas published more than 50 articles in leading academic journals. 